Supporting information

\title{
Probing the In-Situ Redox Behavior of Selenium on Pyrite Surface by Scanning Electrochemical Microscopy
}

\author{
Jingyi Wang, ${ }^{1}$ Lei Xie, ${ }^{1}$ Sijia Li, ${ }^{1}$ Jianmei Wang, ${ }^{2}$ Jiansheng Zhang, ${ }^{3}$ Hongbo Zeng ${ }^{1, *}$ \\ ${ }^{1}$ Department of Chemical and Materials Engineering, University of Alberta, Edmonton, AB, T6G \\ 1H9, Canada \\ ${ }^{2}$ Heavy Machinery Engineering Research Center of Education Ministry, Taiyuan University of \\ Science and Technology, Taiyuan 030024, China \\ ${ }^{3}$ Department of Energy and Power Engineering, Tsinghua University, Beijing, 100084, China
}

*Corresponding author. E-mail: hongbo.zeng@ualberta.ca (H. Zeng); phone +1-780-492-1044 


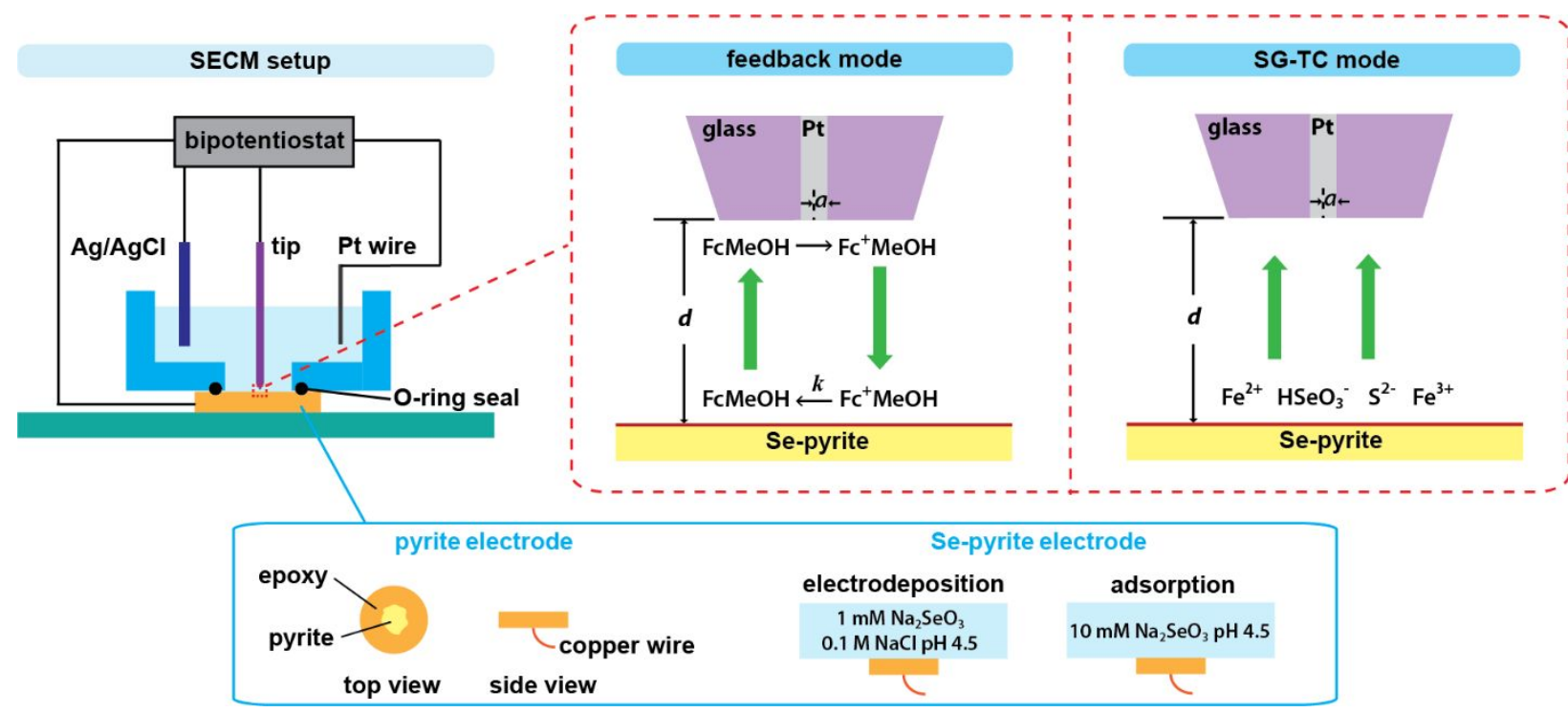

Figure S1. Schematic of the preparation of pyrite and Se-pyrite electrodes and experimental setup of electrochemical and SECM characterization of Se-pyrite surface. The feedback mode was employed to position the Pt tip and characterize the surface conductivity of Se-pyrite. The released species from Se-pyrite were probed by the Pt tip under the SG-TC mode.

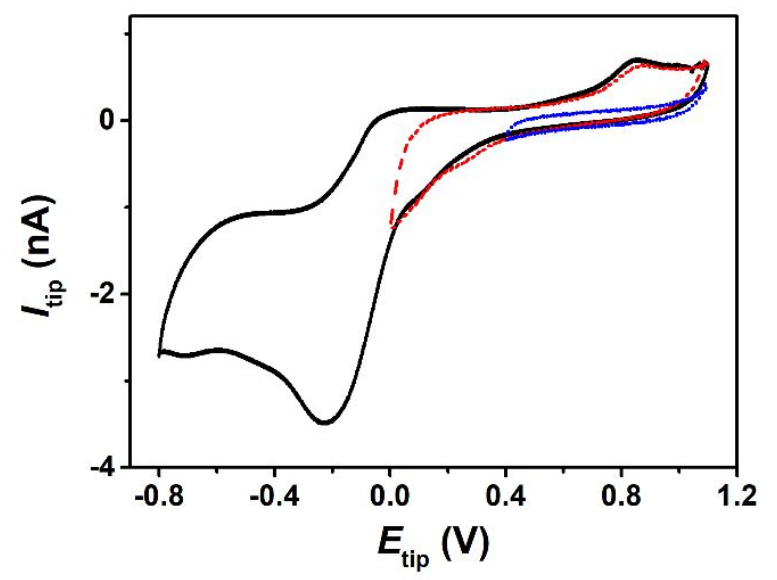

Figure S2. CV curves of Pt tip in $1 \mathrm{mM} \mathrm{Na}_{2} \mathrm{SeO}_{3}$ and $0.1 \mathrm{M} \mathrm{NaCl} \mathrm{pH} 4.5$ with different switch potentials: - $-0.8 \mathrm{~V}$ (black solid line), $0 \mathrm{~V}$ (red dashed line) and $0.4 \mathrm{~V}$ (blue dotted line). 


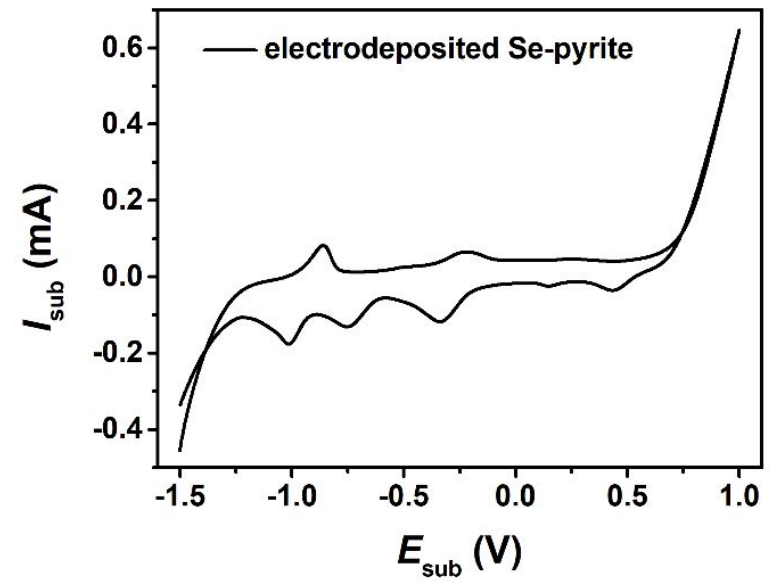

Figure S3. CV curve of electrodeposited Se-pyrite in $0.1 \mathrm{M} \mathrm{NaCl} \mathrm{pH} 4.5$.

(a)

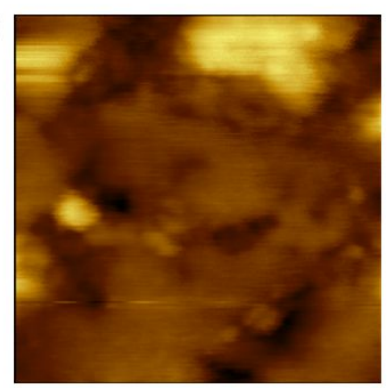

$15 \mathrm{~nm}$

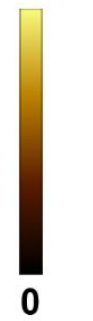

(b)

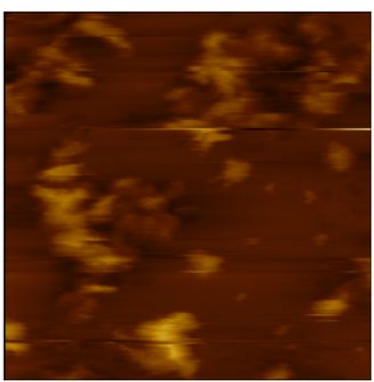

$80 \mathrm{~nm}$

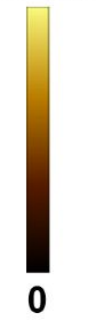

Figure S4. AFM images of (a) pyrite and (b) electrodeposited Se-pyrite in $1 \mathrm{mM} \mathrm{Na}_{2} \mathrm{SeO}_{3}$ and $0.1 \mathrm{M} \mathrm{NaCl}$ at $\mathrm{pH}$ 4.5. Image size: $1 \times 1 \mu \mathrm{m}^{2}$. 

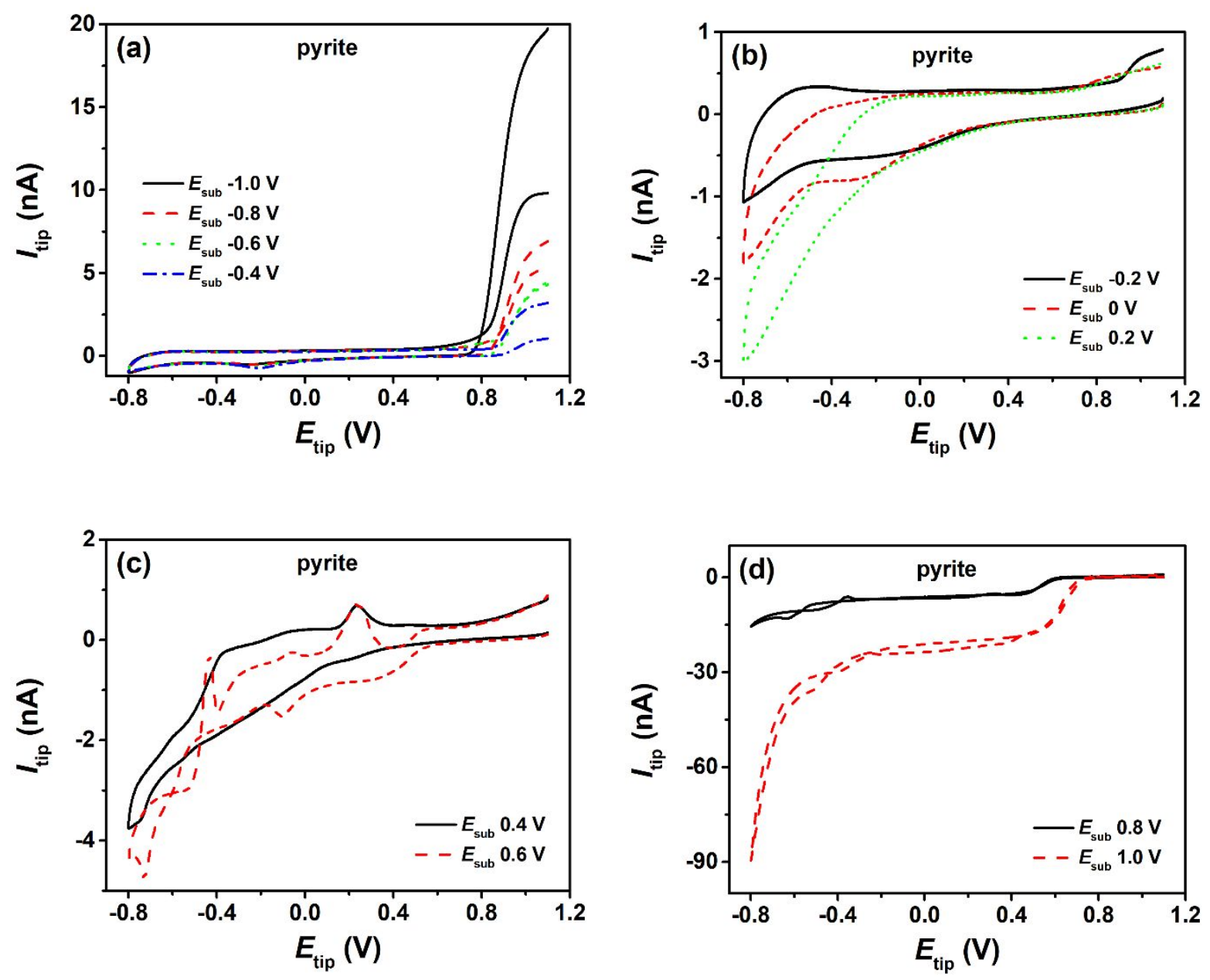

Figure S5. $\mathrm{CV}$ curves of $\mathrm{Pt}$ tip in $0.1 \mathrm{M} \mathrm{NaCl} \mathrm{pH}$ 4.5. The Pt tip was placed $10 \mu \mathrm{m}$ above the pyrite substrate at various potentials: (a) $-1.0 \mathrm{~V},-0.8 \mathrm{~V},-0.6 \mathrm{~V}$ and $-0.4 \mathrm{~V}$, (b) $-0.2 \mathrm{~V}, 0 \mathrm{~V}$ and 0.2 $\mathrm{V}$, (c) $0.4 \mathrm{~V}$ and $0.6 \mathrm{~V}$, and (d) $0.8 \mathrm{~V}$ and $1.0 \mathrm{~V}$. Potential scan rate: $0.1 \mathrm{~V} / \mathrm{s}$. 


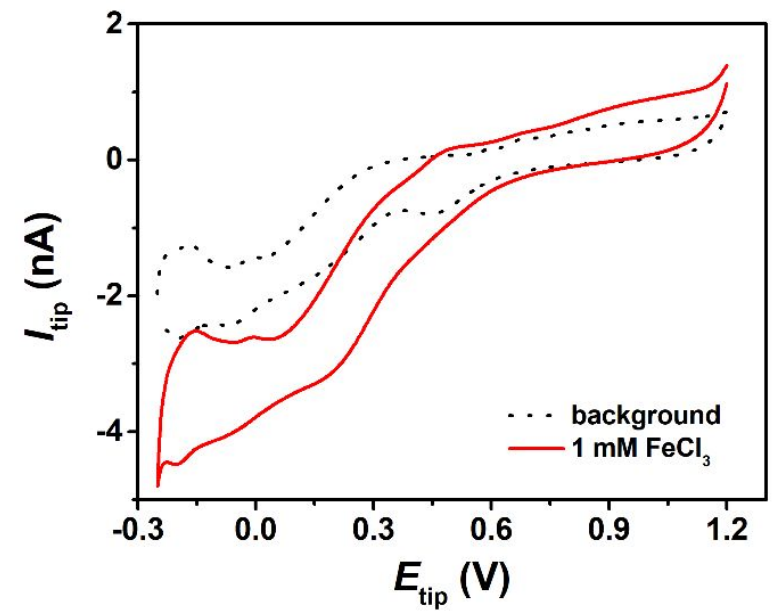

Figure S6. CV curves of Pt tip in $0.5 \mathrm{M} \mathrm{H}_{2} \mathrm{SO}_{4}$ with (red solid line) and without (black dotted line) $1 \mathrm{mM} \mathrm{FeCl}$.

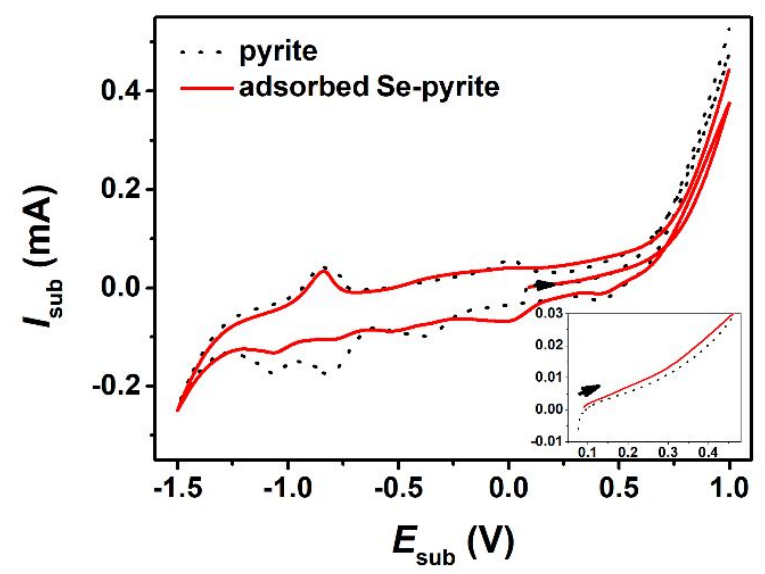

Figure S7. CV curves of pyrite (black dotted line), adsorbed Se-pyrite (red solid line) in $0.1 \mathrm{M}$ $\mathrm{NaCl} \mathrm{pH} \mathrm{4.5.} \mathrm{Inset} \mathrm{shows} \mathrm{the} \mathrm{details} \mathrm{of} \mathrm{the} \mathrm{initial} \mathrm{potential} \mathrm{scan} \mathrm{segments.}$ 